\title{
A Mixed-Methods Approach to Analyze Shared Epistemic Agency in Jigsaw Instruction at Multiple Scales of Temporality
}

\author{
Jun Oshima ${ }^{1 *}$, Ritsuko Oshima ${ }^{2}$, Wataru Fujita ${ }^{3}$
}

\begin{abstract}
The purpose of this study was to propose a mixed-methods approach to analyzing shared epistemic agency in jigsaw instruction from multiple temporal perspectives, and to evaluate its effectiveness by examining actual datasets. We employed a combination of socio-semantic network analysis (SSNA) and in-depth dialogical discourse analysis as a mixed-methods approach, and analyzed discourse transcripts by university students engaged in jigsaw instruction. First, we graphically depicted a quantitative measure of shared epistemic agency at the group level and identified pivotal points of discourse where students might engage in an epistemic action toward alleviating a lack of knowledge. Then, we conducted dialogical discourse analysis of the segments around the pivotal points to describe students' collaboration practices. SSNA represented the quantitative nature of shared epistemic agency with $60 \%$ accuracy and provided a new way to look at it as a distribution of pivotal points for alleviating a lack of knowledge across all processes of jigsaw group activities. The dialogical discourse analysis of the discourse segments identified by SSNA further described dialogical patterns in the shared epistemic agency and each student's contribution to them.
\end{abstract}

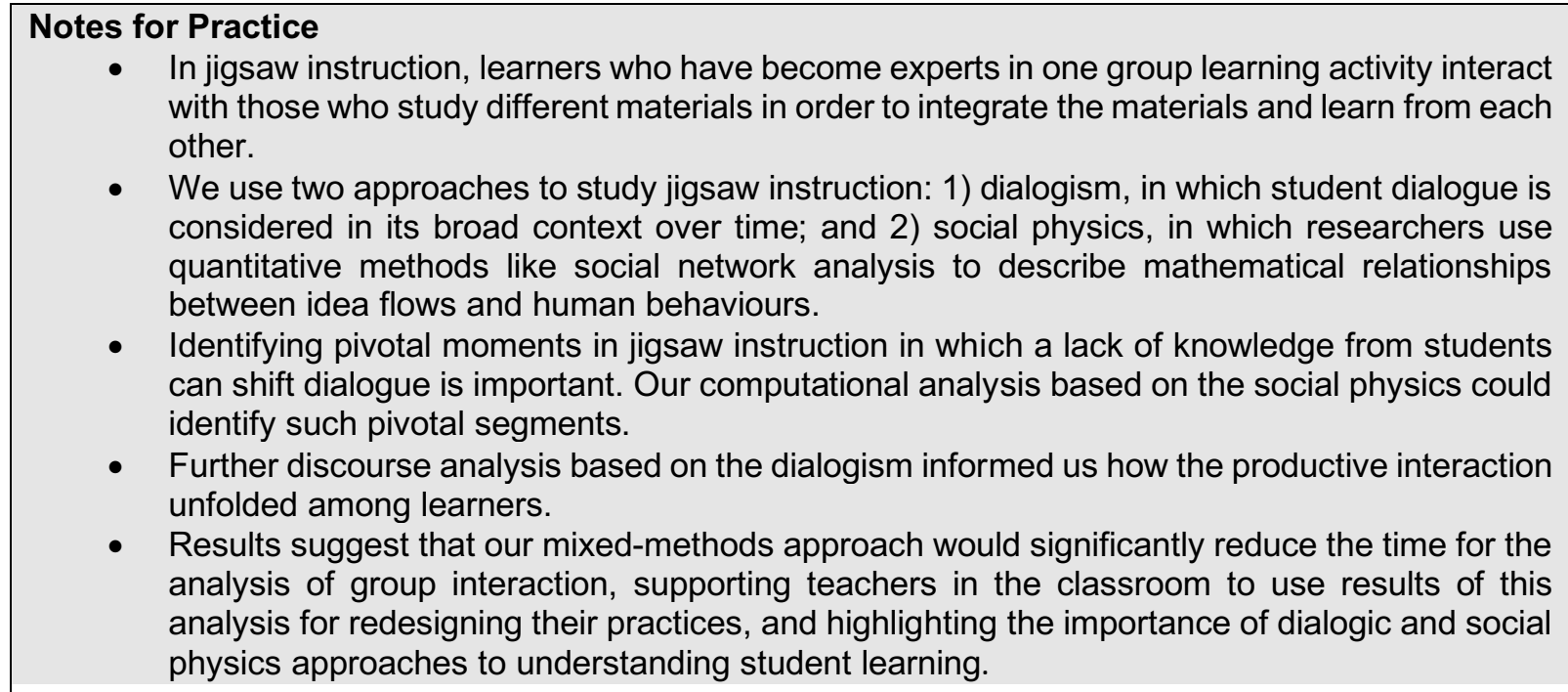

\section{Keywords}

Mixed-methods research, socio-semantic network analysis, dialogical discourse analysis, shared epistemic agency, collaborative learning, jigsaw instruction.

Submitted: 02/02/17 - Accepted: 11/22/17 - Published: 04/09/18

Corresponding author ${ }^{1}$ Email: joshima@inf.shizuoka.ac.jp Address: Research and Education Center for the Learning Sciences, Shizuoka Univ. 836 Oya, Shizuoka-shi, SHIZUIKA, Japan, 422-8529

2Email: roshima@inf.shizuoka.ac.jp Address: Research and Education Center for the Learning Sciences, Shizuoka Univ. 836 Oya, Shizuoka-shi, SHIZUIKA, Japan, 422-8529

${ }^{3}$ Email: fujitawataru@softes.co.jp Address: Graduate School of Informatics, Shizuoka Univ. 3-5-1, Johoku, Naka-ku, Hamamatsu-shi, Shizuoka, Japan, 432-8011 


\section{Introduction}

\subsection{Epistemic Agency as a Goal of Instruction in the Knowledge Age}

According to the knowledge-creation metaphor of learning (Paavola \& Hakkarainen, 2005), students are expected to be involved in the practice of knowledge creation through collaborative construction of knowledge objects (Bereiter, 2002). Regarding knowledge creation in the classroom, Scardamalia (2002) discussed collective cognitive responsibility for contributing ideas toward collective knowledge advancement. She defined epistemic agency as intentional engagement in collective knowledge advancement, and proposed such agency as a new goal for instruction in the knowledge age (Scardamalia, Bransford, Kozma, \& Quellmalz, 2012).

Damşa, Kirschner, Andriessen, Erkens, and Sins (2010) further analyzed shared epistemic agency by placing greater focus on agency at the group level. Based on the previous conceptualization of agency (Bandura, 2001; Emirbayer \& Mische, 1998; Palonen \& Hakkarainen, 2000; Scardamalia, 2002; Schwartz \& Okita, 2004; Stahl, 2006; Wertsch, Del Rio, \& Alvarez, 1995), they further proposed shared epistemic agency as "a capacity that enables groups to deliberately carry out collaborative, knowledge-driven activities with the aim of creating shared knowledge objects." Shared epistemic agency is a significant extension of the concept of epistemic agency, as it comprises individual intentionality for collective activity, as proposed by Scardamalia (2002), and focuses more acutely on the group level of agency during collaborative activity (Stahl, 2006). Damşa et al. (2010) conceptualized learning as a phenomenon taking place through continuous collaboration with the aim of creating new knowledge through work on shared objects. Although many previous studies suggested the importance of shared epistemic agency in discussing learning as knowledge creation, most studies did not examine this construct in such a way to evaluate and improve student practices in the classroom. In their study, Damşa et al. (2010) aimed to create a theoretical framework of shared epistemic agency by reviewing previous studies related to human agency and revising their hypothetical framework through analysis of real data collected during university students' collaboration in project-based learning.

Damşa et al. (2010) proposed two dimensions of shared epistemic agency, each of which has multiple categories of actions. The first dimension is epistemic actions that contribute to the conceptual and physical progress of the shared knowledge objects (Bereiter, 2002; Schwartz \& Okita, 2004). In their epistemic actions, students are expected to engage in developing and translating their ideas into tangible knowledge objects for further knowledge creation. The second dimension is regulative actions focused on the process of regulating students' own collaboration in their activity, such as engaging in object-oriented work and its management (Bandura, 2001; Emirbayer \& Mische, 1998; Palonen \& Hakkarainen, 2000; Scardamalia, 2002). Because we focus on the epistemic dimension of actions in this study, we discuss its categories of actions in more detail below.

The analysis offered by Damşa et al. (2010) proposed four main categories of epistemic actions. The first category of actions is creating awareness. It is essential for students to be aware of a lack of knowledge and problematic situations when exercising shared epistemic agency. As emphasized in previous studies, students' awareness of a lack of knowledge for themselves as well as other members in their collaborative group is an essential component of epistemic agency (Palonen \& Hakkarainen, 2000; Stahl, 2006). The second category of actions is alleviating a lack of knowledge. This category of actions includes examining provided sources, collecting additional information, and structuring new concepts. In this category of actions, students are involved in integrating existing knowledge, but not necessarily seeking a deeper understanding of this knowledge. The third category comprises actions of creating shared understanding. In this category of epistemic actions, students attempt to appropriately adjust the knowledge level among members in a group and attain a shared understanding of ideas and knowledge for the further creation of knowledge objects. These actions include sharing information from sources, giving meaning to new concepts, discussing misunderstandings, sharing ideas and knowledge, and reframing problems (Russel, 2002; Scardamalia, 2002). The final category is generative collaborative actions that delineate productive aspects of shared epistemic agency. This category includes generating new ideas (Scardamalia, 2002; Schwartz \& Okita, 2004), collaborative uptake of ideas (Suthers, 2006), negotiating ideas (Edwards, 2005), reframing knowledge objects, and revising ideas and objects based on the constructive use of feedback.

Thus, when students in groups engage in shared epistemic agency, they conduct the wholly joint epistemic actions of 1) being aware of their lack of knowledge, 2) alleviating this lack of knowledge, 3) creating shared understanding, and 4) generative collaboration. Furthermore, in the regulative dimension that we do not focus on in this study, students also engage in 1) projection by setting goals and creating joint plans; 2) regulation by monitoring and reflecting on their own advancement; and 3) relation by transcending conflicts, redirecting critical feedback, and creating space for others' contributions. In a recent study, Damşa (2014) further proposed that agency in collaboration is multilayered and that students should use both epistemic agency (at the individual level) and shared epistemic agency (at the group level) when intentionally engaging in productive collaboration. 


\subsection{A Mixed-Methods Approach Driven by the Multivocality Approach to Examine Shared Epistemic Agency at Multiple Scales of Temporality}

An assessment approach for evaluating multilayered agency by learners has not yet been established. Because the agency in collaborative learning should appear at either the individual (Scardamalia, 2002) or the group level (Damşa, 2014; Damşa et al., 2010) across different time scales, any single analytic approach would be unable to adequately examine both. In most studies of collaborative learning in the learning sciences, researchers use qualitative methods to examine and measure how learners interact with one another. Because discourse involved in collaborative learning is improvisational and emergent (e.g., Sawyer, 2013), researchers have long viewed moment-by-moment qualitative analyses of interactions between learners as the required method of analysis. Along with this traditional approach, Damşa and colleagues used qualitative and in-depth discourse analysis to identify and test indicators (i.e., epistemic actions in discourse), but we see several opportunities to improve on this approach from both practical and methodological perspectives. First, from a practical perspective, the qualitative approach is not feasible outside of research settings. Researchers often take years to analyze data derived from transcripts in order to gain insights on the mechanisms of human learning. This time scale is simply not feasible for practitioners. In order to teach effectively, classroom practitioners need to evaluate their students' progress day by day, and revise their instructional approach on an ongoing basis. Thus, increased efficiency in performing this type of analysis is an important aim in the field of learning analytics. Second, from a methodological perspective, although in-depth discourse analysis is productive, it fails to provide a macro view needed for between-group comparisons. Damşa et al. (2010) provided an analysis of discourse segments that demonstrated significant differences between two groups of participants, but their selection of the specific fragmented discourse pieces was not based on any objective criteria. In other words, if others had seen the same discourse transcripts, they may have selected different segments for inclusion. This methodological problem could arise from differences in epistemological stances held by two different communities of researchers (e.g., Johnson \& Onwuegbuzi, 2006; Johnson, Onwuegbuzi, \& Turner, 2007; Morgan, 2007). In the present study, we aimed to address the above problems through use of a productive multivocality approach (Suthers, Lund, Rosé, Teplovs, \& Law, 2013) involving pragmatic consideration of the epistemic voices each author contributes to the project.

The term "multivocality" is derived from a seminal work by Bakhtin (1981) discussing the presence of multiple "voices" in texts. The term refers to the multiple voices of researchers who engage in the collective discourse of a field, such as the learning sciences. An assumption of the multivocality approach is that we can advance our knowledge in the learning sciences through the challenge of making multiple isolated epistemologies open to each other so that researchers from different epistemological camps will be more explicit in the belief system behind their methodologies. In a book attempting this multivocality approach (Suthers et al., 2013), researchers from different disciplines engaged in productive discourse by analyzing shared datasets of social interaction in learning contexts from their own epistemological perspectives and methodologies.

One example dataset provided in this book was discourse among first-year university students engaging in collaborative problem-solving in chemistry (Sawyer, Frey, \& Brown, 2013a). From the results of an in-depth qualitative analysis, Sawyer, Frey, and Brown (2013b) concluded that two groups (Gillian vs. Matt) differed significantly in their strategic approaches. Based on conversation analysis of the two groups, Sawyer et al. (2013b) described the profiles of the two groups. The Gillian group went beyond pure calculation by discussing conceptual foundations of what they had learned, and engaging in collaborative knowledge construction through mutual reflection on ideas. Conversely, the Matt group was involved in calculation activities without explicit recognition of what they had learned. The Gillian group exercised their shared epistemic agency toward engagement in collective knowledge advancement.

We (the first and the second authors in this paper) approached the same discourse dataset using a different methodology: socio-semantic network analysis (SSNA). In SSNA, matrices of words within paragraphs or sentences are used as data (Schaffer et al., 2009; Oshima, Oshima, \& Matsuzawa, 2012) rather than social actions like citations or comments. Links between word nodes are created by calculating their co-occurrence frequencies within units of analysis. The socio-semantic network and its structural change can reveal how ideas develop over the course of interactions between participants. This approach was adopted in recent computer-supported collaborative learning (CSCL) studies to analyze student roles in collaboration and to detect productive interaction patterns (e.g., Ma, Matsuzawa, Chen, \& Scardamalia, 2016). The original discourse transcript was converted into a bipartite graph of vocabulary and conversation turns (or discourse exchanges), and a socio-semantic network (of vocabulary) was constructed (Figure 1). The total value of degree centrality of a vocabulary network served as the primary network indicator. This value was recalculated based on aggregative discourse segments whenever a new discourse exchange was added.

For a network with n nodes, the normalized degree centrality, $\mathrm{C}^{\prime} \mathrm{d}(\mathrm{i})$, of node $\mathrm{i}$ is

$$
C_{d}^{\prime}(i)=\frac{1}{n-1} \sum_{j=1}^{n} a_{i j}
$$


where aij is the adjacency matrix for each pair of nodes $(\mathrm{i}, \mathrm{j})$. The total value of degree centrality is calculated as

$$
\sum_{i=1}^{n} C_{d}^{\prime}(i)
$$

at any point in time during an episode of discourse. When a new discourse exchange is added, the network structure may be changed by the addition of new nodes or links between new or existing nodes. Temporal change in the indicator was depicted visually as a graph with discourse exchanges plotted along the horizontal axis and the indicator on the vertical axis. We also indicated pivotal points of discourse when students might engage in collective knowledge advancement. In addition, we further evaluated individual agency by calculating individuals' contributions to the whole socio-semantic network (Oshima, Matsuzawa, Oshima, \& Niihara, 2013). Applying both qualitative (Sawyer et al., 2013b) and quantitative (Oshima et al., 2013) approaches based on different epistemic stances to the same discourse datasets was found to be complementary and productive. Qualitative and quantitative methods provided both unique and replicated findings (Fujita, 2013).

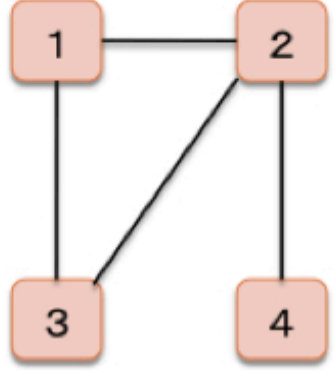

Network of Discourse
Units

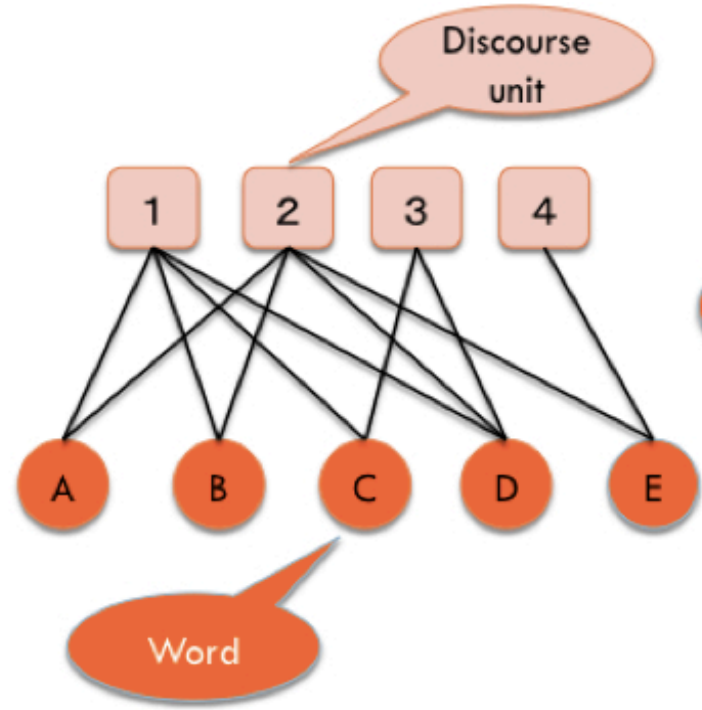

\section{Bipartite Graph of Discourse Units $\times$ Words}

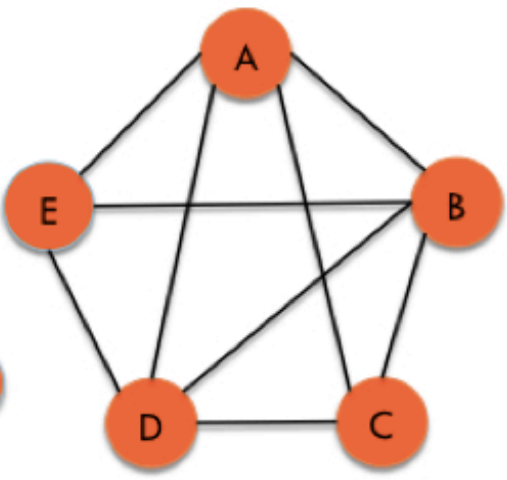

Network of Words

Figure 1. Procedure of creating a socio-semantic network (right).

Based on our experience in the multivocality project, we propose a mixed-methods approach to analyzing shared epistemic agency in a more comprehensive way to address both practical and methodological problems. In the multivocality approach, multiple research groups with different epistemic voices approached the same discourse datasets from different perspectives. In this study, we transform the multivocality approach into a mixed-methods approach by which we analyze discourse from multiple epistemic stances while asking specific research questions. One epistemic stance we adopted in this study is that of computational social science or social physics (e.g., Lazer et al., 2009; Palla, Barabási, \& Vicsek, 2007; Pentland, 2014). In social physics, researchers use quantitative methods like social network analysis to describe mathematical relationships between idea flows and human behaviours. Palla et al. (2007), for instance, examined the basic relationships characterizing community evolution in groups of scientists and of mobile telephone users. Results indicated differing patterns of community evolution in groups of differing sizes. Large groups are sustained when they can dynamically modify their membership, whereas small groups are stable when membership is kept unchanged. It was also found that the time members commit to their community is an indicator of the community's lifetime. Thus, in social physics, computational power and human behavioural data can be used to explore the mechanisms of both community development and knowledge advancement.

The second epistemic stance taken when conducting the present research is dialogism (Bakhtin, 1981, 1986; Mead, 1922; Rommetveit, 1974). In dialogical discourse analysis (e.g., Valsiner, 2002; Wertsch, 1991, 2008), researchers take the epistemic stance that meaning is not found in logical structure or dictionary definitions, but rather in the relation between the utterance and the broad context, such as the participants. Discourse is considered to be situated in the sense that a social context is a necessary condition for utterances to be meaningful. In contrast to the assumption that language structure plays a role as a source of meaning, dialogism focuses on the reality of language-in-context. Meaning in the utterances is determined not only 
by what interlocutors are doing, but also by what they have previously done with the words and what they will do in the future. Moreover, meaning in an utterance always implies an audience (Bakhtin, 1986). Speakers speak from their audience's perspectives, and audiences attempt to listen from the speaker's perspective (Rommetveit, 1974). Based on these premises, researchers use qualitative methods to analyze discourse by carefully examining dialogue in its context.

By referring to recent arguments on mixed-methods research designs (e.g., Johnson \& Onwuegbuzi, 2006; Johnson, Onwuegbuzi, \& Turner, 2007; Morgan, 2007), we designed our mixed-methods approach as a sequential application of quantitative and qualitative methods while placing an equal emphasis on each. In the first phase of our mixed-methods approach to examining shared epistemic agency, we conducted SSNA of discourse data to examine the change in the state of shared epistemic agency within groups. By using a quantitative indicator (the total value of degree centrality coefficients), we identified pivotal points of discourse exchanges where students engaged in shared epistemic agency across an extended period of the process (i.e., a duration of several hours), and compared learning processes between groups. In the second phase of our investigation, after quantitatively examining the state of their agency and identifying pivotal points of discourse exchanges, we conducted in-depth dialogical discourse analysis to examine how students in a group interact with one another to exercise their epistemic agency over a short period of time. Within the context of collaborative learning, we apply our mixed-methods approach to jigsaw instruction to facilitate shared epistemic agency developed in the learning sciences.

\subsection{Jigsaw Instruction as a Learning Environment for Students to Engage in their Shared Epistemic Agency}

In the learning sciences, many studies have endeavored to design learning environments to facilitate students' collective knowledge advancement (Sawyer, 2014). Through such efforts, effective collaborative learning arrangements have been identified, and more detailed instructional interventions have been discussed in the literature (Miyake \& Kirschner, 2014). One such instructional method is jigsaw instruction. In jigsaw instruction, learners are expected to engage in two different phases of an activity. One is the expert group activity, where they collaboratively work on the same materials. Their collaboration in the expert group facilitates constructive interaction (Miyake, 1986) among learners who meet their individual goals to become experts of their assigned material. Learners are encouraged not only to collaboratively develop their conceptual understanding, but also to prepare for their future task - the jigsaw group activity. After learning their materials in the expert group, they join the jigsaw group where learners who studied different materials gather and integrate the different sources of knowledge collaboratively. In this phase of the jigsaw group activity, students are predicted to engage in productive interaction within multiple zones of proximal development depending on different knowledge sources (e.g., Brown \& Campione, 1996). With respect to any one component of the learning activity, one student is an expert in that domain and teaches the other group members. This teaching-learning process is repeated multiple times.

Although studies have demonstrated that jigsaw instruction is effective for facilitating conceptual understanding as well as collective knowledge advancement (e.g., Miyake \& Kirschner, 2014), few studies have examined in detail a process of how learners take their responsibility to contribute to the collective knowledge advancement through their collaboration, i.e., shared epistemic agency. In this study, therefore, we examined the process of students' collective knowledge advancement in the jigsaw instruction by applying our mixed-methods approach.

\subsection{Research Purpose and Research Questions}

As an "Implementation and Adoption Contribution," this study aimed to propose a mixed-methods approach to analyzing shared epistemic agency in collaborative learning as an extension of our previous work (Oshima et al., 2012, 2013), and to demonstrate its effectiveness by applying the approach to examining a learning environment designed for facilitating shared epistemic agency (i.e., jigsaw instruction).

To do so, we asked the following research questions. First, we examined whether our quantitative indicator of shared epistemic agency in collaborative discourse can identify pivotal points of discourse exchanges from all transcripts. The indicator we proposed in this study is the total value of degree centrality coefficients in the vocabulary network of discourse. A category of epistemic actions we thought could be computationally approached is alleviating a lack of knowledge. In evaluating the temporal change in the indicator across discourse exchanges from the beginning to the end, we identified discourse exchanges that led the indicator to increase significantly. The significant increase in the indicator suggests pivotal points of discourse where learners may engage in synthesizing knowledge (i.e., epistemic actions of alleviating a lack of knowledge). We expect that we can evaluate each group's progress in the learners' shared epistemic agency by identifying its initial phase of the cyclic process through the four categories of epistemic actions. How many times a group of students experiences this cyclic process and how it starts are significant issues for us to examine. In addition, we modified our procedure for detecting the pivotal points from a visual inspection method to a more precise computational algorithm that selected the pivotal points of discourse exchanges. Specifically, the algorithm identified points with an increase in value greater than the mean increase of discourse exchanges after omitting discourse exchanges having a decrease or no change in the total degree centrality. After identifying the pivotal points of discourse in this way, we conducted the in-depth dialogical discourse analysis 
of all the identified segments to validate whether the discourse segments detected by SSNA were related to learners' epistemic actions of alleviating a lack of knowledge. Second, we examined how the quantitative method in our mixed-methods approach provided us with useful insights on group differences in shared epistemic agency between two groups participating in our jigsaw instruction. The number of pivotal points of discourse detected and the members who contributed to the identified discourse exchanges were examined. Third, in our in-depth discourse analysis, we compared collaboration practices between the two groups by carefully describing how they engaged in their dialogues toward shared epistemic agency.

The first question, and part of the second research question, are related to the quantitative method's validity and usefulness in analyzing epistemic agency, which has traditionally been analyzed via qualitative approaches. The remaining part of the second question and the third question are related to the examination of our proposed mixed-methods approach through its application to the actual context of collaborative learning.

\section{Methods}

Collaborative reading comprehension, which is a form of jigsaw instruction, was implemented as part of an intensive course during the summer term of a teacher certification program at a Japanese public university. The course was taught over the course of four consecutive days, and the jigsaw instruction activity was conducted during the first day and a half. The second author was the course instructor. Toward fulfilling the course requirements, eight third-year undergraduate students in the engineering department participated in this study. The overall goal of the course for students was to learn basic concepts of computer-supported collaborative learning (CSCL) in order to appropriately apply lesson plans. The more specific goal for students during the collaborative reading comprehension component was to understand basic principles of designing learning environments (Bransford, Brown, \& Cocking, 1999).

\subsection{Collaborative Reading Comprehension}

Collaborative reading comprehension is an activity based on jigsaw instruction methods (Aronson \& Patnoe, 2011; Brown \& Campione, 1996; Miyake \& Kirschner, 2014). It encourages learners to engage in collaborative knowledge creation through building an understanding of multiple document resources (Figure 2). Students were first placed in expert groups after listening to an instructor's brief lecture on "the learning environment," which was the target concept. In each expert group, two students collaboratively read and constructed an understanding of one document, which they then explained to others in jigsaw groups. Through expert group collaboration, each student produced a summary by taking notes while listening to an audiobook on an iPod and discussing their ideas based on their notes. After the expert groups had finished, jigsaw groups were formed; these groups consisted of one student from each expert group. Students in the jigsaw groups worked to integrate the ideas contained in the four different documents based on the student experts' explanations for each document. After discussing the four documents in the jigsaw group activity, the students reported how ideas from the documents were related to one another, and interpreted them with reference to the basic framework of learning environments in the Knowledge Forum CSCL system (Scardamalia \& Bereiter, 2014).

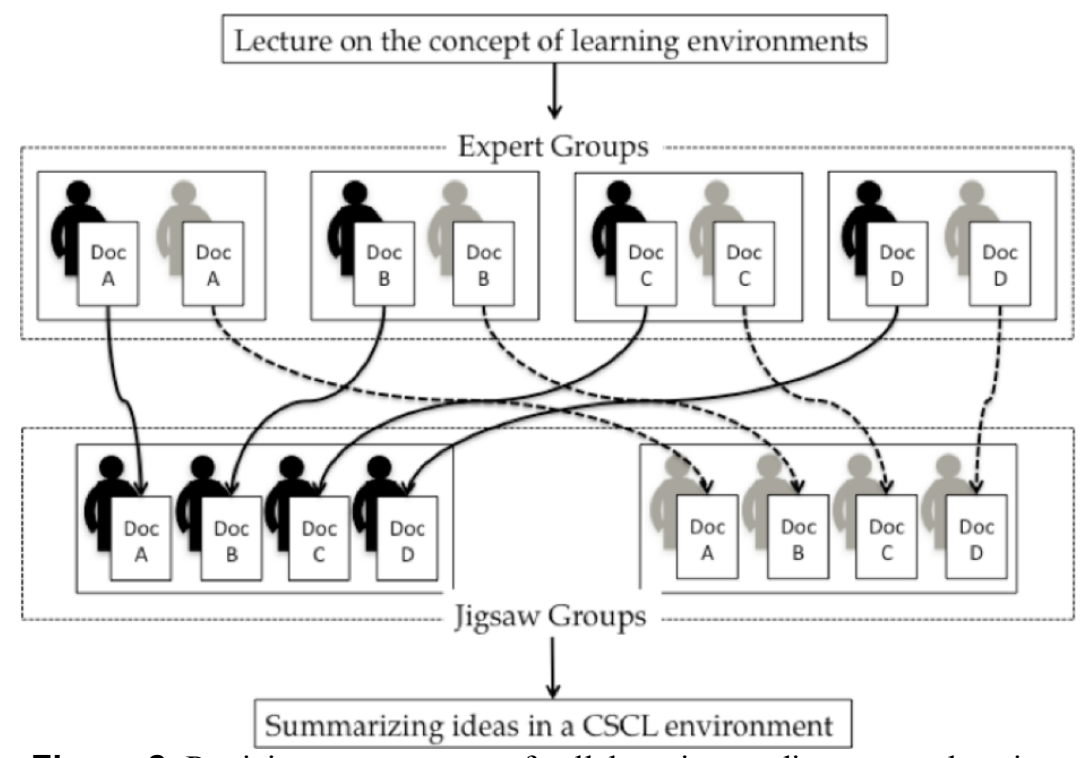

Figure 2. Participatory structure of collaborative reading comprehension. 
Documents used in the expert activity came from a book on how people learn (Inagaki \& Hatano, 1989). All documents were written in Japanese. We selected four chapters of the book covering four principles of designing learning environments: learner-centred, knowledge-centred, assessment-centred, and community-centred. Each chapter was transcribed and given as an audiobook assignment to an expert group. We instructed students to take notes in order to summarize and organize ideas from their audiobooks in relation to the concept of learning environments. In jigsaw groups, students brought their notes of the ideas summarized from the audiobook, and discussed how the ideas from different audiobook chapters could be integrated to advance their understanding of the principles of learning environments. To facilitate the knowledge creation process, we further provided students with a whiteboard, on which a diagram of the learning environment proposed by Bransford et al. (1999) was drawn, as well as sticky notes for inscribing and manipulating their ideas as knowledge objects in the shared space.

\subsection{Mixed-Methods Approach}

As discussed in the previous section, we applied a mixed-methods approach to analyze shared epistemic agency in collaborative reading comprehension by shedding light on alleviating a lack of knowledge. All discourse activities in expert and jigsaw groups were video-recorded and transcribed verbatim. Particular focus was placed on discourse activities in the jigsaw group. Students engaged in discourse exchange 1,021 times in jigsaw group A, and 921 times in jigsaw group B. Jigsaw group activity was of particular interest because students were expected to actively engage in shared epistemic agency through creating new ideas by integrating their knowledge with the notes taken in the expert group activity used as knowledge objects.

\subsubsection{SSNA for Identifying Pivotal Points for Alleviating a Lack of Knowledge}

To identify pivotal points in discourse exchange for alleviating a lack of knowledge, we conducted SSNA using the procedure described below. An assumption we held was that we would be able to represent collective knowledge advancement as a structural change in a network of vocabulary that students used in their discourse. The vocabulary in this context refers to words used for representing argumentations in the audiobooks that students listened to and summarized. The structure of vocabulary refers to meaningful links between words in a sentence or exchange. When students used words in their exchanges, we assumed that they attempted to create meaningful links between words.

For our SSNA, we used KBDeX (Oshima et al., 2012) to visually represent a socio-semantic network, and repeatedly calculate the total value of the degree centrality coefficients in a vocabulary network whenever a new discourse exchange was added. To analyze transcription datasets with $\mathrm{KBDeX}$, we first had to prepare a vocabulary list for the application to automatically create a bipartite graph of words $\mathrm{x}$ exchanges. The first author and a trained graduate student independently detected nouns that they thought represented the authors' arguments in the four audiobooks and came up with 305 nouns. Then, we ran KBDeX to visually represent a socio-semantic network and recalculate the total value of the degree centrality coefficients in a vocabulary network exchange by exchange. KBDeX provides socio-semantic network visualization and an automatically created graph of the trajectory of the total value of the degree centralities (upper right window in Figure 3).

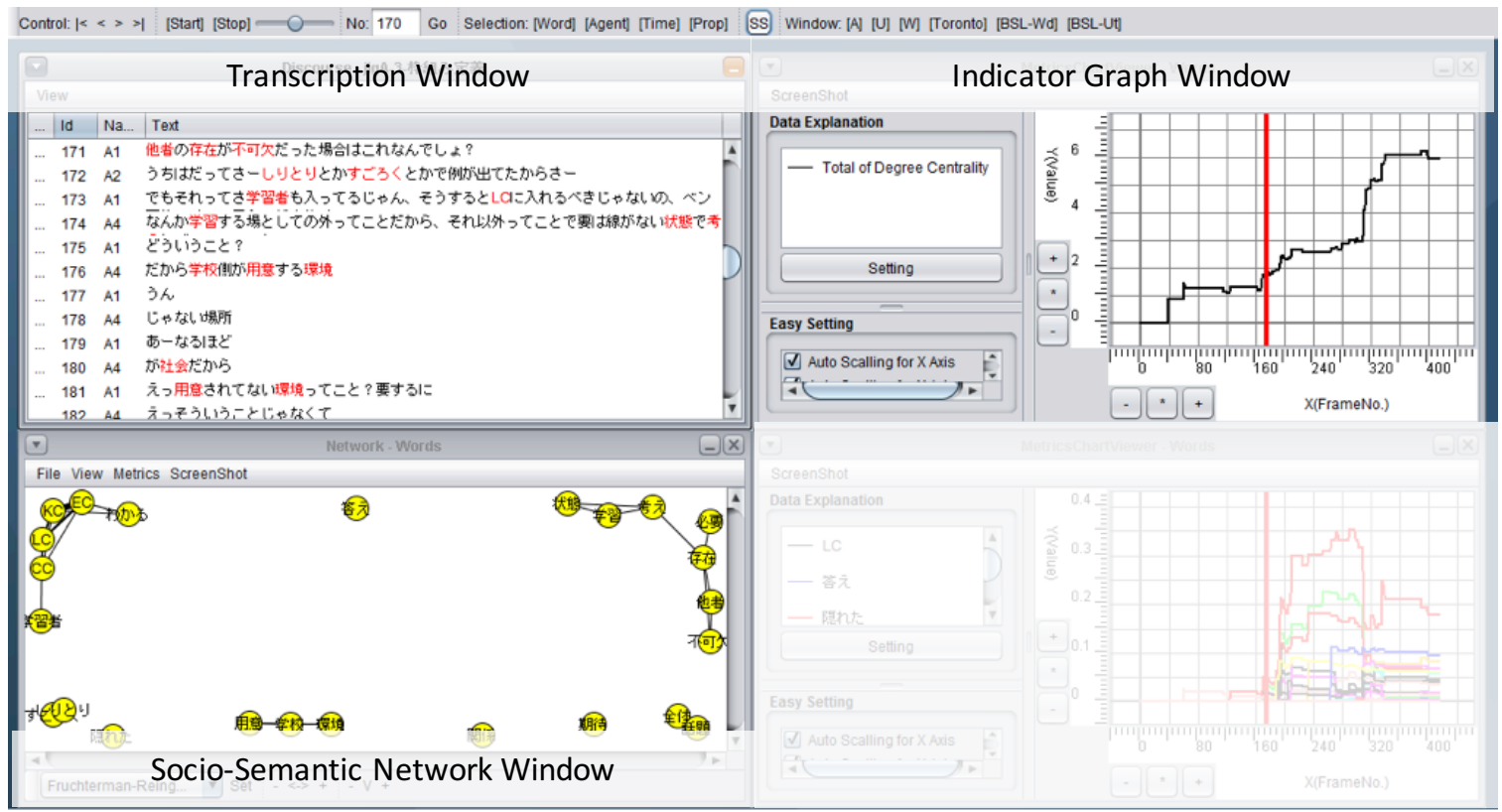

Figure 3. Socio-semantic network analysis with KBDeX. 
For identifying pivotal points, we paid attention to the temporal transition of the total value of degree centralities. When we saw a significant increase in the total value of degree centralities in a vocabulary network from one exchange to another, we assumed that the latter exchange contributed to either making an existing network denser or restructuring an existing network by adding new words in such a way that a more integrated structure was constructed. Thus, a significant increase in the total value of degree centralities may indicate that students in a group engaged in alleviating a lack of knowledge. As stated previously, we identified the pivotal points of alleviating a lack of knowledge as discourse exchanges with the increase in the indicator greater than the mean increase of all discourse exchanges after omitting discourse exchanges having a decrease or no change in the total degree centrality ( $95 \%$ of all discourse exchanges), and identified the individuals in a group who were involved in the pivotal points of exchanges as significant contributors.

As described further in the next sub-section, we tested whether the automatically detected discourse exchanges could be categorized as alleviating a lack of knowledge through our dialogical discourse analysis (our first research question). Subsequently, after examining the rate of accurate detection, we further investigated how many discourse exchanges were recorded as alleviating a lack of knowledge, and which students in a group made a contribution to such exchanges. This type of comparative analysis in the quantitative method had not been done in previous studies, and was a significant contribution of this study. By analyzing the group differences across a scenario of discussing a topic with others, we can identify the relationship between temporality of shared epistemic agency (alleviating a lack of knowledge in this case) and epistemic agents (which students contributed).

\subsubsection{In-depth Dialogical Discourse Analysis for Revealing How Students Exercised their Shared Epistemic Agency}

Our SSNA was conducted using quantitative methods to examine shared epistemic agency as a change in the state of their collective knowledge. Our dialogical discourse analysis, on the other hand, approached the same sets of discourse data at micro-dialogical level (Valsiner, 2002; Wertsch, 1991). We first identified segments of discourse exchanges to figure out how students in a group engage in shared epistemic agency as dialogue by tracing discourse exchanges back from the corresponding pivotal points of discourse exchanges or tracing them following such points. Then, as described in the previous sub-section, we evaluated whether automatically detected pivotal points were related to alleviating a lack of knowledge. Finally, if the sequences of discourse exchanges represented alleviating a lack of knowledge, we further analyzed how individual students in a group dialogically contributed to their shared epistemic agency.

\section{Results}

\subsection{SSNA for Discourse Transcriptions in Collaborative Reading Comprehension}

After reading transcripts of discourse by two jigsaw groups (A and B), the first and third authors held discussions to divide the entire discourse into several discourse scenarios for each group. Here, a scenario refers to sequences of discourse exchanges in which students discussed ideas related to each other. For group A, the whole discourse was segmented into three scenarios. Group B was segmented into two.

For answering our first research question, Figures 4 and 5 demonstrate how the total value of degree centralities transited within scenarios by groups A and B, respectively. Circled discourse exchanges in each graph were identified as pivotal based on our "above mean" algorithm. By conducting dialogical discourse analysis of the discourse exchanges around the pivotal points for validating our algorithm, we found that discourse exchanges identified were related to alleviating a lack of knowledge $(60 \%)$ or awareness of a lack of knowledge $(40 \%)$. Although we did not expect to detect another category of epistemic actions (the awareness of a lack of knowledge), we proceeded to conduct subsequent in-depth dialogical discourse analysis in the following way. For pivotal points of discourse exchanges detected as the awareness of a lack of knowledge, we traced discourse exchanges following them in order to identify the discourse exchanges related to alleviating a lack of knowledge that we could not detect in SSNA. For pivotal points of alleviating a lack of knowledge that we successfully detected, we traced discourse exchanges back from the pivotal points for the purpose of identifying segments for further dialogical discourse analysis.

For answering our second research question, Table 1 shows the number of contributions each student made toward alleviating a lack of knowledge in discourse scenarios. In group A, student A1 was found to be a key contributor toward alleviating a lack of knowledge. In group B, on the other hand, key contributors in discourse were different across two scenarios. Students B2 and B4 made many contributions in the first scenario, but B1 and B2 made many contributions in the second scenario when B4 missed the class. 


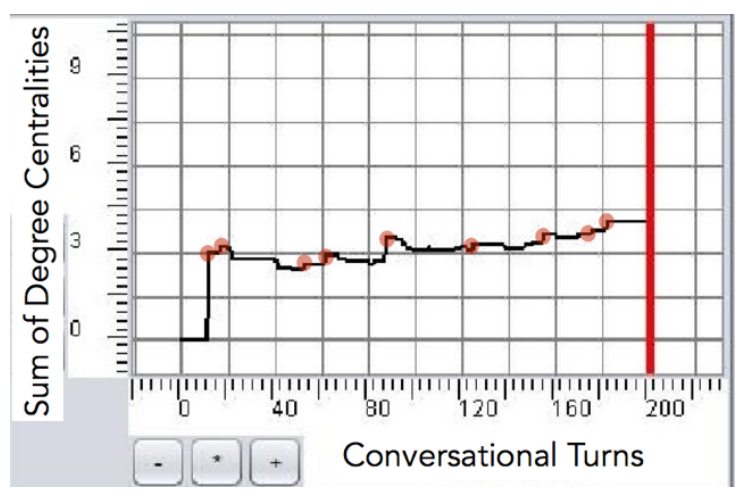

a. Scenario \#1

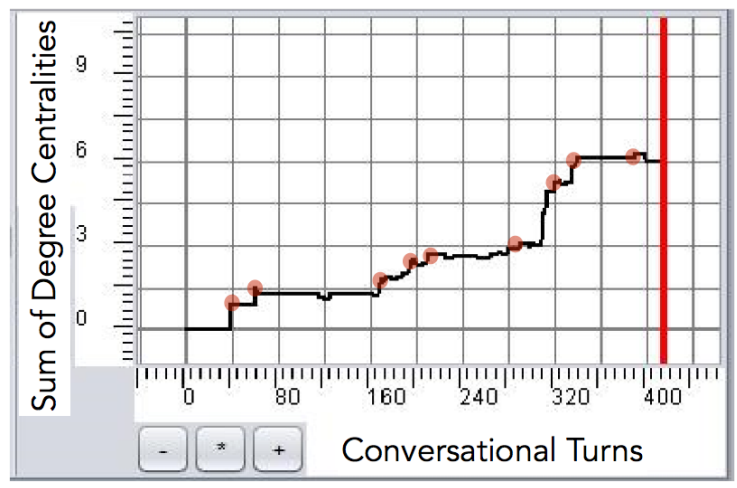

b. Scenario \#2

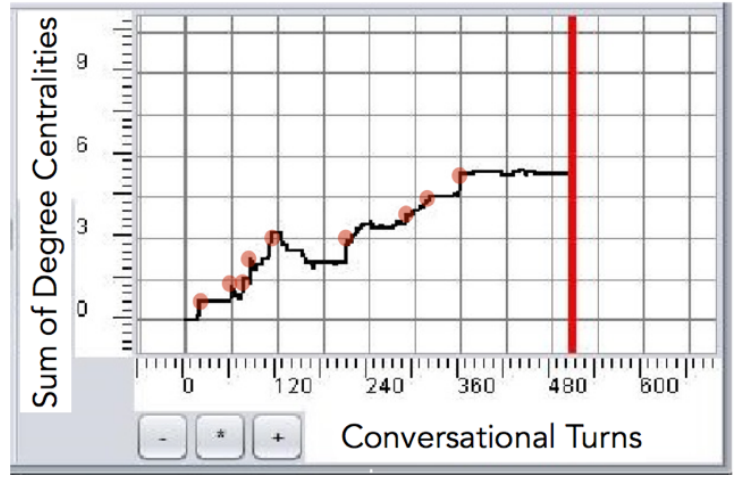

c. Scenario \#3

Figure 4. Transitional changes in the sum of degree centralities in discourse scenarios by jigsaw group A. 


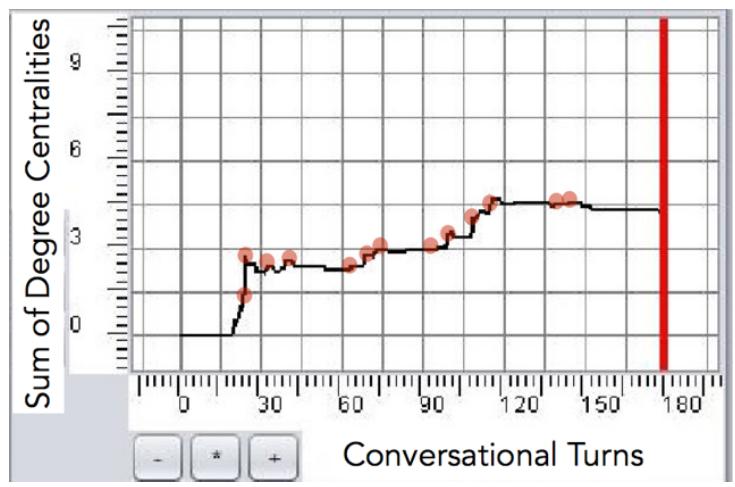

a. Scenario \#1

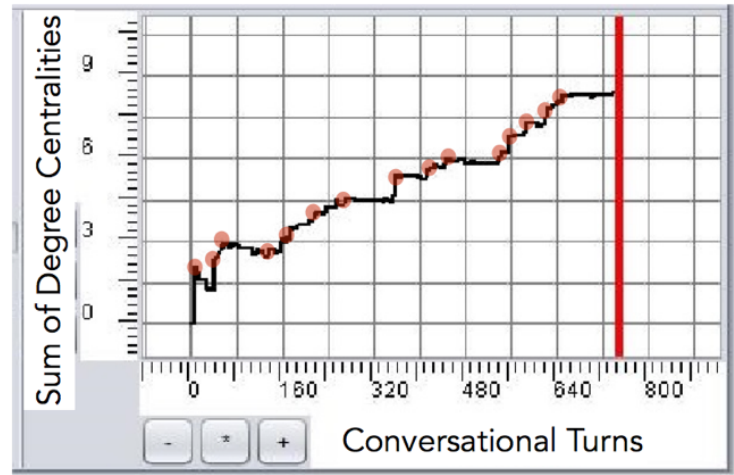

b. Scenario \#2

Figure 5. Transitional changes in the sum of degree centralities in discourse scenarios by jigsaw group B.

Table 1. Frequencies of pivotal contributions by students

\begin{tabular}{lllllll}
\hline & \multicolumn{2}{l}{ Jigsaw Group A } & & \multicolumn{3}{c}{ Jigsaw Group B } \\
\hline Student & Scenario 1 & Scenario 2 & Scenario 3 & Student & Scenario 1 & Scenario 2 \\
\hline A1 & 4 & 7 & 7 & B1 & 1 & 9 \\
\hline A2 & 4 & 0 & 2 & B2 & 5 & 6 \\
\hline A3 & 1 & 2 & 0 & B3 & 2 & 0 \\
\hline A4 & 0 & 0 & 0 & B4 & 5 & Absent \\
\hline
\end{tabular}

\subsection{In-Depth Dialogical Discourse Analysis of Discourse Exchanges Related to Pivotal Points}

After our SSNA of discourse transcripts, we further conducted in-depth dialogical analysis of discourse segments related to the pivotal points for answering our third research question. We report one segment from each jigsaw group. The following is a segment of discourse from group A regarding learner-centred design. The original discourse was in Japanese, and we have translated it into English. Words used in SSNA were in bold.

Student A2: It is not easy for learners to conduct intentional learning when their context does not support them. They need tools for engaging in intentional learning. So, we are discussing the context rather than the learners, aren't we?

Student A1: But it is too simplistic to describe that this is entirely an issue of context because of the existence of tools for students.

Student A3: We had better not say like "OK, this is an issue of context because of tools." 
Student A1: No, we should not. Yesterday, we discussed that the authors argued for community-centred design when they described the context, including peers, tools, and so on, because these factors facilitate students' intention to learn.

Student A3: Yeah, we did.

Student A1: We should not misunderstand the authors' argument. They did not argue that the context, such as peers or tools, determines how students learn. In more precise terms, they argued that the context does facilitate how students intend to learn. These are remarkably different, aren't they?

In the discourse segment, the last discourse exchange by student A1 was identified as pivotal by SSNA. In his last discourse exchange, student A1 alleviated a lack of knowledge about learner-centred design, community-centred design, and their interrelation as discussed in the documents. In the sequence of discourse exchanges, students A2 and A3 were found to engage in epistemic actions for student A1, who ultimately utilized his turn to facilitate their awareness of the problem (i.e., the first turn by student A2, and the third turn by student A3). In jigsaw group A, dialogues for exercising shared epistemic agency were represented by this example of discourse. Student A1 was responsible for ultimately promoting shared understanding towards alleviating their lack of knowledge, and other students (A2, A3, and A4) started sequences of discourse exchanges by creating awareness.

In jigsaw group B, we also found students' established dialogues for their shared epistemic agency toward alleviating a lack of knowledge. However, the dialogical practice in jigsaw group B was different from that in jigsaw group A.

Student B4: B3, in what you said.

Student B3: Yeah.

Student B4: The authors proposed a variety of ideas related to different sections [in the Venn diagram of learning environments]. But all the ideas are related to community-centred design.

Student B3: In chapter 7, I read that the core concept was community-centred design. All ideas are placed in the intersections of community-centred design and others.

Student B4: I agree. I first did think that community-centred design was independent of the three other designs. But, after your idea, I now think that those are overlapping like the Venn diagram. Community-centred design is related to all the others.

Student B2: I also think so.

Student B4: Age is also another factor for designing learning environments, I think. Depending on the age of learners, we have to place a different priority on the four designs. For younger kids, for instance, the knowledge-centred design does not seem to have much priority on designing learning.

In this discourse segment, the last discourse exchange by student B4 was identified as pivotal in SSNA. Student B4 was engaged in integrating the other students' ideas to alleviate the pre-existing lack of knowledge. The difference in dialogical patterns between the two jigsaw groups was that student B4 was also responsible for the awareness of the group's lack of knowledge. He intended to elicit others' ideas by paraphrasing them (i.e., the third discourse exchange). Other students (B3 and B2 in this discourse segment) were engaged in epistemic agency to provide additional information and examine B4's argument. This dialogical pattern was frequently seen in jigsaw group B to engage in their shared epistemic agency.

We serendipitously found another pattern displayed by group B. On the second day, when student B4 missed a class (scenario \#2), other members were engaged in discourse holding different roles. The most remarkable result was that the role of student B1, who had not been active in scenario \#1, changed to one of active engagement, identifying and alleviating the group's lack of knowledge by regulating other group members, just as student B4 had done in scenario \#1.

\section{Discussion}

With discourse transcripts as data, we conducted a mixed-methods approach to analyze shared epistemic agency; specifically, the epistemic actions of alleviating a lack of knowledge during jigsaw instruction. We asked three research questions. First, we examined whether our indicator of alleviating a lack of knowledge in shared epistemic agency was useful for detecting pivotal points of discourse exchanges for the purpose of further in-depth dialogical discourse analysis. Second, we further examined how the quantitative method in our mixed-methods approach provided us with useful insights on group differences in shared epistemic agency between two groups participating in our jigsaw instruction. Finally, in the second phase of our mixed-methods approach, we attempted to examine how students in the two groups engaged in their dialogues for shared epistemic agency. 
With respect to the first research question, SSNA was found to be effective for computationally identifying pivotal points of discourse exchanges for the alleviation of a lack of knowledge or the emergence of awareness. For detecting the pivotal points of discourse exchanges toward alleviating a lack of knowledge, we proposed an algorithm based on the total value of degree centralities of a socio-semantic network of vocabulary. Sixty percent of discourse exchanges that increased the total value of degree centralities of a socio-semantic network over the mean of increases by exchanges were confirmed as alleviating a lack of knowledge through our further dialogical discourse analysis. Although $40 \%$ of the detected exchanges were identified as awareness of a lack of knowledge rather than alleviating it, we could identify pivotal points of discourse exchanges toward alleviating a lack of knowledge by tracing discourse exchanges following the originally identified points rather than tracing back from them. This finding of $40 \%$ of discourse exchanges detected by SSNA was not expected because we had thought that students would not explicitly share their awareness by using the conceptual words used in our SSNA, and it would therefore be difficult to detect awareness with a list of vocabulary terms contained in study documents. On the other hand, alleviating a lack of knowledge, including synthesizing and summarizing their thoughts, was considered representative of an integration process of conceptual words in the study documents. In the particular context of jigsaw instruction, such as collaborative reading comprehension, the participatory structure of jigsaw group activities might facilitate students to share their awareness of a lack of knowledge and alleviate it through collaborative discourse with conceptual words. This possibility should be further examined by using a different context of discourse in a group task format other than jigsaw group activity to test whether we can also detect discourse exchanges toward the awareness of a lack of knowledge as well as the alleviation of it.

Regarding the quantitative method, we should discuss two types of errors in detection for future studies. In the SSNA phase of our mixed-methods approach, we cannot rule out the possibility of type II errors. Namely, the possibility of pivotal points of discourse exchanges that we could not detect by SSNA. To test for type II errors, we must conduct an in-depth dialogical analysis of all the transcripts, and compare results between the dialogical analysis and SSNA. We also identified type I errors. Our detection algorithm led us to the result that $40 \%$ of detected exchanges were not related to alleviating a lack of knowledge, but rather to the awareness of a lack of knowledge. Both categories are related, and valuable epistemic actions to detect by SSNA. However, we must further refine measures for distinguishing between those two actions. In our current research project, we are developing a combination of two centrality measures (i.e., degree centrality and betweenness centrality) to detect each epistemic action in discourse more accurately (e.g., Oshima, Oshima, \& Fujita, 2016).

Concerning our second research question, our quantitative method provides a new way to look at temporal and contextual profiles of shared epistemic agency with a perspective of which group members contributed to epistemic actions of alleviating a lack of knowledge. First, we found that students engaged in the epistemic actions repeatedly across the whole discourse processes (27 times in group A and 28 in group B). Because the structure of a socio-semantic network becomes more complex as their discourse proceeds, pivotal points of discourse exchanges in the later phases would be more crucial than those in the beginning. Although we have not yet examined what pivotal points at different points of time indicate, what we can reveal from the current quantitative analysis is that the both groups of students constantly achieved an advancement of their knowledge. This continuous advancement of their knowledge might be driven by the participatory structure of jigsaw instruction where students with different pieces of knowledge came together to discuss and integrate their ideas. This possibility should also be examined in future studies that compare collaborative discourse between another mode of group work and jigsaw group activities.

Furthermore, contrary to our naive prediction of egalitarian contribution, we found idiosyncratic contribution patterns across members within groups. Some students made more contributions than others. In group A, one student was mostly responsible for the epistemic actions, and this contribution pattern was found to be stable across the three scenarios. Meanwhile, several students made critical contributions in group B, and the contribution pattern changed over time and in response to contextual factors. These group differences in contribution patterns across members are findings that our quantitative method can readily indicate. With a limited amount of data, such as 27 and 28 segments of discourse exchanges by two groups, we may have a possible interpretation of the contribution patterns by group members in their shared epistemic agency. Contribution patterns of the epistemic actions in groups were stable within groups, and any contextual disturbance such as an absence of a member triggers a new pattern. This possibility could also be examined through analyzing more cases of jigsaw group activities.

Although their contributions to the specific epistemic actions within groups were not equally distributed, the dialogical practices occurring in their discourse were rather productive. For the third research question, the in-depth dialogical discourse analysis provided us with rich information toward clarifying how students engage in their dialogues for epistemic actions toward alleviating a lack of knowledge. First, the type of each individual's contribution was found to be stable, indicating that students might have their cultural epistemic practices established through their experiences of being together across several courses before taking this course. In group A, students displayed greater collaboration in regulating their agency, although a specific student contributed most pivotal points of discourse exchange. Meanwhile, specific students in jigsaw group B (B4 and B1) were dominant. Second, it was also found via analysis of group B that students' shared epistemic agency was resilient 
to unpredictable events. Even when a dominant student (B4) was not present, the remaining students in jigsaw group B could maintain their shared epistemic agency through different contribution patterns (student B1, who had been inactive in scenario $\# 1$, took over the regulation of the epistemic actions of the group).

In this study, we argued for epistemic agency as a new goal of instruction, and proposed a mixed-methods approach to examine how students engage in shared epistemic agency in the instructional context of jigsaw instruction. Through implementation and adoption of our mixed-methods approach, we demonstrated a quantitative method to detect pivotal points of discourse exchanges for epistemic actions of alleviating a lack of knowledge. Results indicated $60 \%$ accuracy in detecting pivotal points, and thus suggest a new way of looking at group profiles of shared epistemic agency across all discourse exchanges. As we saw in the sequential process of SSNA and further dialogical discourse analysis, we could more comprehensively examine student epistemic agency compared with the exclusively qualitative approach employed in previous studies. From a practical perspective, we could improve the speed of the analysis in such a way that we can provide practitioners with group profiles in their classrooms a few months after their enactment. This improvement in analytical speed is still not sufficient, but is useful for us to collaboratively think of a new lesson plan with practitioners for the next academic year. From a methodological perspective, our algorithm of detecting pivotal points of discourse exchange was found partially effective and further improvable for other researchers to share their discourse datasets for the purpose of analyzing shared epistemic agency in collaborative learning. Moreover, we can provide colleagues with an objective reason of why we selected specific segments of discourse for further analyzing dialogues in detail. Although we should further elaborate our mixed-methods approach based on the results of this study, an approach like the combination of SSNA and in-depth dialogical discourse analysis would be an engine for researchers to accelerate their research on shared epistemic agency in collaborative learning.

\section{Acknowledgements}

We sincerely acknowledge our anonymous reviewers for their contributions to the improvement of our manuscript. It would not be possible for us to publish our work without their comments and suggestions.

\section{Declaration of Conflicting Interest}

The author(s) declared no potential conflicts of interest with respect to the research, authorship, and/or publication of this article.

\section{Funding}

This study was financially supported by JSPS KAKENHI Grant Number 16H0187.

\section{References}

Aronson, E., \& Patnoe, S. (2011). Cooperation in the classroom: The jigsaw method (3rd ed.). London: Pinter \& Martin.

Bakhtin, M. (1981). The dialogic imagination: Four essays. Austin, TX: University of Texas Press.

Bakhtin, M. (1986). Speech genres and other late essays. Austin, TX: University of Texas Press.

Bandura, A. (2001). Social cognitive theory: An agentic perspective. Annual Review of Psychology, 52, 1-26. http://dx.doi.org/10.1146/annurev.psych.52.1.1

Bereiter, C. (2002). Education and mind in the knowledge age. Hillsdale, NJ: Erlbaum.

Bransford, J. D., Brown, A. L., \& Cocking, R. R. (Eds.) (1999). How people learn: Brain, mind, experience, and school. Washington, DC: National Academies Press.

Brown, A. L., \& Campione, J. C. (1996). Psychological theory and the design of innovative learning environments: On procedures, principles, and systems. In L. Schauble \& R. Glaser (Eds.), Innovations in learning: New environments for education (pp. 289-325). Mahwah, NJ: Lawrence Erlbaum Associates.

Damşa, C. I. (2014). Shared epistemic agency and agency of individuals, collaborative groups, and research communities. In J. L. Polman, E. A. Kyza, D. K. O’Neill, I. Tabak, W. R. Penuel, A. S. Jurow, K. O’Connor, T. Lee, \& L. D’Amico (Eds.), Learning and Becoming in Practice: Proceedings of the International Conference of the Learning Sciences (ICLS '14), 23-27 June 2014, Boulder, CO, USA (Vol. 1, pp. 440-447). International Society of the Learning Sciences.

Damşa, C. I., Kirschner, P. A., Andriessen, J. E. B., Erkens, G., \& Sins, P. H. M. (2010). Shared epistemic agency: An empirical study of an emergent construct. Journal of the Learning Sciences, 19(2), 143-186. http://dx.doi.org/10.1080/10508401003708381

Edwards, A. (2005). Relational agency: Learning to be a resourceful practitioner. International Journal of Educational Research, 43(3), 168-182. http://dx.doi.org/10.1016/j.ijer.2006.06.010

Emirbayer, M., \& Mische, A. (1998). What is agency? American Journal of Sociology, 103, 962-1023. 10.1086/231294 
Fujita, N. (2013). Critical reflections on multivocal analysis and implications for design-based research. In D. Suthers, K. Lund, C. Rose, C. Teplovs, \& N. Law (Eds.), Productive Multivocality in the Analysis of Group Interactions (pp. 435458). New York: Springer. http://dx.doi.org/10.1007/978-1-4614-8960-3 24

Inagaki, K., \& Hatano, G. (1989). How people learn: The world of everyday cognition. Tokyo, Japan: Chuo-koronsha [in Japanese].

Johnson, R. B., \& Onwuegbuzi, A. J. (2006). Mixed methods research: A research paradigm whose time has come. Educational Researcher, 33(7), 14-26. http://dx.doi.org/10.3102/0013189X033007014

Johnson, R. B., Onwuegbuzi, A. J., \& Turner, L. A. (2007). Toward a definition of mixed methods research. Journal of Mixed Methods Research, 1(2), 112-133. http://dx.doi.org/10.1177/1558689806298224

Lazer, D., Pentland, A., Adamic, L., Aral, S., Barabási, A.-L., Brewer, D., ... Van Alstyne, M. (2009). Computational social science. Science, 323, 721-723. http://dx.doi.org/10.1126/science.1167742

Ma, L., Matsuzawa, Y., Chen, B., \& Scardamalia, M. (2016). Community knowledge, collective responsibility: The emergence of rotating leadership in three knowledge building communities. In C. K. Looi, J. L. Polman, U. Cress, \& P. Reimann (Eds.), Transforming Learning, Empowering Learners: Proceedings of the 12th International Conference of the Learning Sciences (ICLS '16), 20-24 June 2016, Singapore (Vol. 1, pp. 615-622). International Society of the Learning Sciences. http://dx.doi.org/10.22318/icls2016.80

Mead, G. H. (1922). A behavioristic account of the significant symbol. Journal of Philosophy, 19(6), 157-163. http://dx.doi.org/10.2307/2939827

Miyake, N. (1986). Constructive interaction and the iterative process of understanding. Cognitive Science, 10, 151-177. http://dx.doi.org/10.1016/S0364-0213(86)80002-7

Miyake, N., \& Kirschner, P. A. (2014). The social and interactive dimensions of collaborative learning. In K. Sawyer (Ed.), The Cambridge handbook of the learning sciences, 2nd ed. (pp. 418-438). New York: Cambridge University Press.

Morgan, D. L. (2007). Paradigms lost and pragmatism regained: Methodological implications of combining qualitative and quantitative methods. Journal of Mixed Methods Research, 1(1), 48-76. http://dx.doi.org/10.1177/2345678906292462

Oshima, J., Matsuzawa, Y., Oshima, R., \& Niihara, Y. (2013). Application of social network analysis to collaborative problem solving discourse: An attempt to capture dynamics of collective knowledge advancement. In D. Suthers, K. Lund, C. Rose, C. Teplovs, \& N. Law (Eds.), Productive multivocality in the analysis of group interactions (pp. 225242). New York: Springer. http://dx.doi.org/10.1007/978-1-4614-8960-3 12

Oshima, J., Oshima, R., \& Fujita, W. (2016). Refinement of semantic network analysis for epistemic agency in collaboration. In C. K. Looi, J. Polman, U. Cress, \& P. Reimann (Eds.), Transforming Learning, Empowering Learners: Proceedings of the 12th International Conference of the Learning Sciences (ICLS '16), 20-24 June 2016, Singapore (pp. 1191-1192). International Society of the Learning Sciences.

Oshima, J., Oshima, R., \& Matsuzawa, Y. (2012). Knowledge building discourse explorer: A social network analysis application for knowledge building discourse. Educational Technology Research \& Development, 60, 903-921. http://dx.doi.org/10.1007/s11423-012-9265-2

Paavola, S., \& Hakkarainen, K. (2005). The knowledge creation metaphor: An emergent epistemological approach to learning. Science \& Education, 14, 535-557. http://dx.doi.org/10.1007/s11191-004-5157-0

Palla, G., Barabási, A.-L., \& Vicsek, T. (2007). Quantifying social group evolution. Nature, 446, 664-667. http://dx.doi.org/10.1038/nature05670

Palonen, T., \& Hakkarainen, K. (2000). Patterns of interaction in computer-supported learning: A social network analysis. In B. Fishman \& S. O'Connor-Divelbliss (Eds.), Facing the Challenges of Complex, Real-World Settings: Proceedings of the 4th International Conference of the Learning Sciences (ICLS 2000), 14-17 June 2000, Ann Arbor, MI, USA (pp. 334-339). Mahwah, NJ: Erlbaum.

Pentland, A. (2014). Social physics: How good ideas spread: The lessons from a new science. London, UK: Scribe Publications. http://dx.doi.org/10.1007/s11138-014-0276-6

Rommetveit, R. (1974). On message structure: A framework for the study of language and communication. London: Wiley.

Russel, A. (2002, April). The role of epistemic agency and knowledge building discourse to foster interprofessional practice in a Canadian hospital. Paper presented at the annual meeting of the American Education and Research Association. New Orleans, LA, USA. http://ikit.org/fulltext/2002AERAAnn.pdf

Sawyer, K. (2013). Qualitative methodologies for studying small groups. In C. E. Hmelo-Silver, C. A. Chinn, C. K. K. Chan, \& A. M. O'Donnell (Eds.), The international handbook of collaborative learning (pp. 126-148). New York: Routledge.

Sawyer, K. (Ed.) (2014). The Cambridge handbook of the learning sciences, 2nd ed. New York: Cambridge University Press.

Sawyer, K., Frey, R., \& Brown, P. (2013a). Peer-led team learning in general chemistry. In D. Suthers, K. Lund, C. Rose, C. Teplovs, \& N. Law (Eds.), Productive Multivocality in the Analysis of Group Interactions (pp. 183-190). New York: Springer. http://dx.doi.org/10.1007/978-1-4614-8960-3_9 
Sawyer, K., Frey, R., \& Brown, P. (2013b). Knowledge building discourse in peer-led team learning (PLTL) groups in firstyear general chemistry. In D. Suthers, K. Lund, C. Rose, C. Teplovs, \& N. Law (Eds.), Productive multivocality in the analysis of group interactions (pp. 191-204). New York: Springer. http://dx.doi.org/10.1007/978-1-4614-8960-3 10

Scardamalia, M. (2002). Collective cognitive responsibility for the advancement of knowledge. In B. Smith (Ed.), Liberal education in a knowledge society (pp. 67-98). Chicago, IL: Open Court.

Scardamalia, M., \& Bereiter, C. (2014). Knowledge building and knowledge creation: Theory, pedagogy, and technology. In K. Sawyer (Ed.), The Cambridge handbook of the learning sciences, 2nd ed. (pp. 397-417). New York: Cambridge University Press.

Scardamalia, M., Bransford, J., Kozma, B., \& Quellmalz, E. (2012). New assessments and environments for knowledge building. In P. Griffin, B. McGraw, \& E. Care (Eds.), Assessment and teaching of 21st century skills (pp. 231-300). New York: Springer Science+Business Media. http://dx.doi.org/10.1007/978-94-007-2324-5 5

Schaffer, D. W., Hatfield, D., Svarovsky, G. N., Nash, P., Nulty, A., Bagley, E., ... Mislevy, R. (2009). Epistemic network analysis: A prototype for 21 st century assessment of learning. International Journal of Learning and Media, 1(2), 121. http://dx.doi.org/10.1162/ijlm.2009.0013

Schwartz, D., \& Okita, S. (2004). The productive agency in learning by teaching. http://aaalab.stanford.edu/papers/Productive Agency in Learning by Teaching.pdf

Stahl, G. (2006). Group cognition: Computer support for building collaborative knowledge. Cambridge, MA: MIT Press.

Suthers, D. (2006). A qualitative analysis of collaborative knowledge construction through shared representations. Research and Practice in Technology Enhanced Learning, 1(2), 1-28. http://dx.doi.org/10.1142/S1793206806000147

Suthers, D. D., Lund, K., Rosé, C. P., Teplovs, C., \& Law, N. (Eds.). (2013). Productive multivocality in the analysis of group interactions. New York: Springer.

Valsiner, J. (2002). Forms of dialogical relations and semiotic autoregulation within the self. Theory \& Psychology, 12(2), 251-265. http://dx.doi.org/10.1177/0959354302012002633

Wertsch, J. V. (1991). Voices of the mind: A sociocultural approach to mediated action. Cambridge, MA: Harvard University Press.

Wertsch, J. V. (2008). The narrative organization of collective memory. Ethos, 36(1), 120-135. http://dx.doi.org/10.1111/j.1548-1352.2008.00007.x

Wertsch, V. J., Del Rio, P., \& Alvarez, A. (1995). Sociocultural studies: History, action, and mediation. In J. V. Wertsch, P. del Rio, \& A. Alvarez (Eds.), Sociocultural studies of mind (pp. 1-36). Cambridge, UK: Cambridge University Press. 